Teatro no Ensino de Química: Relato de Experiência

\author{
Ventura, B.; Neves, R. L.; Ribeiro, V. G. P.; Vale, M. R.; Guedes, I.; \\ Mazzetto, S. E.*
}

Rev. Virtual Quim., 2018, 10 (4), 824-840. Data de publicação na Web: 19 de julho de 2018

http://rvq.sbq.org.br

\title{
Theater in Chemistry Teaching: Experience Report
}

Abstract: Teaching Chemistry currently demands from teachers an increasing use of new tools. The traditional way sometimes produces resistance and apathy of students. Some interesting methods have been proposed to overcome these drawbacks. One is the scientific theater, which combines art and science on the stage. Here we report on experiments involving six plays (League of Science, The Alchemist, Are We What We Eat, Lampião and Maria Bonita in Search of the Chemistry of Love, The Chemical Avengers and Doctorate in the Chemistry of Love) performed to students and teachers with different levels of formal education in Chemistry. By means of the analysis of questions, debates and conversations with the audience about the plays, we analyze how efficient their use to stimulate the learning and knowing of Chemical concepts can be.

Keywords: Chemistry teaching; ludic activities; science and art; scientific theater.

\section{Resumo}

O Ensino de Química atualmente exige dos professores um uso cada vez maior de novas ferramentas. A maneira tradicional às vezes produz resistência e apatia dos alunos. Alguns métodos interessantes foram propostos para superar essas desvantagens. Um deles é o teatro científico, que combina arte e ciência no palco. Foram relatadas experiências envolvendo seis peças (A Liga da Ciência, O Alquimista, Somos o que comemos, Lampião e Maria Bonita em busca da Química do Amor, Os Vingadores Químicos e Doutorado em Química do Amor) realizadas para estudantes e professores de diferentes níveis de educação formal em Química. Através da análise de questões, debates e conversas com o público sobre as peças, analisou-se a eficiência do uso delas para estimular a aprendizagem e conhecer os conceitos químicos.

Palavras-chave: Ensino de Química; Atividades Lúdicas; Ciência e Arte; Teatro Científico.

\footnotetext{
* Universidade Federal do Ceará, Laboratório de Produtos e Tecnologia em Processos (LPT), Campus do Pici, CEP 60455-900, Fortaleza-CE, Brasil.

Mselma@ufc.br

DOI: $\underline{10.21577 / 1984-6835.20180060}$
} 


\section{Teatro no Ensino de Química: Relato de Experiência}

\section{Bruno Ventura, ${ }^{a}$ Rebeka Lúcio e Neves, ${ }^{b}$ Viviane G. P. Ribeiro, ${ }^{a}$ Marcus Raimundo Vale, ${ }^{b}$ Ilde Guedes, ${ }^{b}$ Selma Elaine Mazzetto ${ }^{a, *}$}

${ }^{a}$ Universidade Federal do Ceará, Laboratório de Produtos e Tecnologia em Processos (LPT), Departamento de Química Orgânica e Inorgânica, Campus do Pici, CEP 60455-900, FortalezaCE, Brasil.

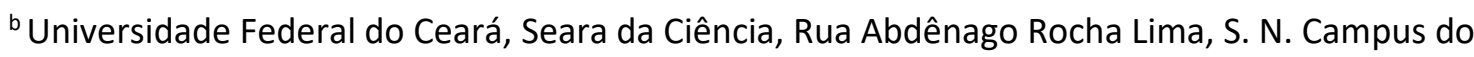
Pici, CEP 60440-614, Fortaleza-CE, Brasil.

*selma@ufc.br

Recebido em 13 de junho de 2017. Aceito para publicação em 12 de julho de 2018

\section{Introdução}

1.1. O Lúdico no Ensino de Química

1.2. O Teatro Científico

\section{Metodologia}

2.1. A Montagens das Peças

\section{Resultados e Discussão}

4. Conclusões

\section{Introdução}

Atualmente diversos estudos relatam a preocupação em despertar o interesse dos alunos da educação básica para o aprendizado de Química. ${ }^{1-5}$ Dificuldades em memorizar fórmulas e entender alguns conceitos abstratos, são talvez os grandes desafios dos alunos ao estudar Química. ${ }^{1}$

A sociedade moderna é dominada pela dinâmica de novas tecnologias, que exigem mudanças em várias atividades profissionais, incluindo ensinar. Talvez o ensino tradicional de Química empregado nas instituições de ensino precise, não de uma mudança profunda, mas talvez do uso de novas ferramentas, como a Música, o Teatro, Jogos Educativos, entre outros, para ajudar aos alunos a conhecerem e entenderem melhor os conceitos dessa disciplina

\subsection{O Lúdico no Ensino de Química}

A busca por ferramentas diversificadas para contribuir no processo de ensinoaprendizagem estimulou vários educadores a investirem em alternativas metodológicas para o Ensino de Química.

Muitos autores defendem que as ferramentas lúdicas geram divertimento, possuindo diversas vantagens em sala de 
aula, pois retira o aluno da situação monótona de espectador, tornando-o um ser ativo no processo de aprendizagem. ${ }^{6-8}$ Além disso, elas aproximam os alunos dos professores, pois essas atividades costumam favorecer a coletividade, posto que muitas ações priorizam o trabalho em grupo. Por mais complexo que seja o assunto, quando trabalhado de forma lúdica paradigmas de conteúdos abstratos são desmistificados, contribuindo para o entendimento de conceitos químicos, situação importante, principalmente para os iniciantes nessa ciência.

As atividades lúdicas são tidas como elementos motivadores e facilitadores da construção de conceitos científicos no processo de ensino-aprendizagem. O lúdico pode ser utilizado como promotor da aprendizagem nas práticas escolares, possibilitando a aproximação dos alunos ao conhecimento científico. ${ }^{9}$ No contexto atual, educadores têm se dedicado à criação e ao desenvolvimento de atividades lúdicas. Cunha $^{10}$, por exemplo, constatou que ao utilizar jogos didáticos, o aspecto lúdico provocou mudanças no comportamento dos estudantes, passando a apresentar uma maior rapidez na aprendizagem em função da forte motivação observada.

No entanto, deve-se ter cuidado ao utilizar atividades lúdicas no Ensino de Química, pois estas não podem conduzir a uma interpretação de aula exclusivamente divertida, que deixe o aprendizado em segundo plano. O lúdico precisa ser visto como uma linguagem motivadora para os alunos, despertando a curiosidade e levandoos a compreender os conteúdos. No entanto, esta linguagem não deve ser utilizada para substituir os conteúdos tradicionais, muito menos ser a fórmula para "revolucionar" o Ensino de Química.

Soares ${ }^{11}$ investigou métodos e formas de aplicação de jogos envolvendo conceitos químicos, os quais demostraram ser uma excelente alternativa para despertar o interesse dos alunos. Silveira ${ }^{12}$ revelou uma experiência exitosa envolvendo a Música, encontrando importantes relações com a
Química. Ainda contribuindo neste aspecto, acompanhando a formação de alunos do curso de Licenciatura em Química das Universidades Federal e Estadual do Rio Grande do Norte, Sousa Júnior ${ }^{13}$ verificou que o teatro científico mostrou ser uma forma lúdica e uma alternativa promissora para o Ensino de Química.

Robaina ${ }^{14}$ defende que o lúdico faz com que o educando construa a sua concepção de mundo e, com isso, obtenha ótimos resultados no campo do desenvolvimento emocional, cognitivo, social, bem como em outras áreas do crescimento humano. Trabalhar com ludicidade constitui-se em um importante recurso para o educando desenvolver suas habilidades e competências na resolução de problemas, favorecendo a apropriação de conceitos e atendendo aos anseios daqueles que ainda estão em processo de desenvolvimento.

\subsection{O Teatro Científico}

A relação entre Ciência e Teatro teve como marco inicial a dramaturgia Vida de Galileu (1956), de Bertold Brecht, artista que buscou elementos da metodologia científica em seu método teatral. Ainda no século XX outras peças do gênero surgiram, como: $O s$ Físicos (1960), de Friedrich Dürremant e o Caso Oppenheimer (1964) de Heinar Kipphardt.

No Brasil, alguns grupos têm se dedicado ao teatro científico ${ }^{(\mathrm{a})}$ : Seara da Ciência,

(a)UFC = Universidade Federal do Ceará, Seara da Ciência, Fortaleza-CE;

UFSCar = Universidade Federal de São Carlos, Ouroboros, São Carlos-SP;

UERN = Universidade do Estado do Rio Grande do Norte, Fanáticos da Química, Mossoró-RN

UECE = Universidade Estadual do Ceará; $\underline{\text { Tubo }}$ de Ensaio, Itapipoca-CE;

UEMA = Universidade Estadual do Maranhão, LetraFisicoQuímic, Caxias-MA; 
Ouroboros, Fanáticos da Química, Tubo de Ensaio, LetraFísicoQuímic, Química em Cena, Show da Química, Alquimia, dentre outros. Vale destacar que todos eles vêm recebendo o devido reconhecimento da comunidade científica através de premiações das suas peças teatrais.

O teatro científico se caracteriza pela composição de peças que abordam conteúdos científicos. ${ }^{15}$ Peças desse gênero são caracterizadas por conter temas envolvendo história da ciência ou que usam a ciência como metáfora. A literatura reporta o desenvolvimento de diversos trabalhos neste gênero, ${ }^{16-18}$ como Silveira et $\mathrm{al}^{16}$ que identificaram através do estudo teórico da peça Copenhague, a qual explora o dilema entre dois dos principais cientistas envolvidos na Teoria Quântica (Niels Bohr e Werner Heisenberg), o estabelecimento de uma ponte entre a Ciência e a Arte. Souza Júnior et $\mathrm{a}^{17}$ analisaram a experiência de formação inicial de professores de Química através da participação no grupo de teatro Química em Cena, verificando que a prática teatral favoreceu o desenvolvimento de habilidades que incidem diretamente sobre a formação docente. Nunes et al ${ }^{18}$ utilizaram o teatro de bonecos para apresentar e discutir Ciência com estudantes da Educação Básica, através de situações presentes no cotidiano.

No Brasil, os grupos que desenvolvem trabalhos envolvendo o teatro científico estão vinculados, em sua grande maioria, à Instituições de Ensino Superior e à Museus de Ciências, os quais se reúnem anualmente em evento específico, criado desde 2007 pelo Núcleo Ouroboros de Divulgação Científica, denominado de Ciência em Cena. Segundo sua criadora, Dra. Karina Omuro Luppeti, o objetivo do evento é promover o encontro de grupos teatrais de diferentes regiões do

UFRN = Universidade Federal do Rio Grande do Norte, Química em Cena, Natal-RN;

UFBA $=$ Universidade Federal da Bahia, Salvador-BA; Show da Química, Salvador-BA; UNESP = Universidade Estadual Paulista, Alquimia, Araraquara-SP.
Brasil, que utilizam Ciência em suas peças. $\mathrm{O}$ objetivo é trocar experiências de modo que tanto os participantes do encontro quanto aqueles que prestigiam os espetáculos possam usufruir das atividades científicas e culturais, podendo resultar em novos trabalhos de divulgação científica envolvendo essa temática. ${ }^{19}$

O teatro científico une Ciência com aspectos teatrais como mímica, interpretação, mudanças de vozes e adereços cênicos com um forte apelo visual. É importante ressaltar que, embora seja uma atividade lúdica que traz elementos artísticos em sua essência, existe uma preocupação constante em inserir conceitos corretos, atuais e relevantes para a Ciência, Tecnologia e Sociedade. Somente com o equilíbrio entre Arte e Ciência, de maneira divertida e pedagógica, é que se estará atingindo os objetivos do teatro científico, que é despertar nos alunos o interesse pela Ciência e seus desdobramentos. Neste gênero, a plateia geralmente não é formada por um público genérico como no teatro convencional, mas sim por estudantes, acadêmicos e educadores.

Aqueles que desconhecem esse tipo de atividade lúdica educacional, frequentemente levantam questões como: 0 teatro científico ensina? Como escrever uma dramaturgia desse gênero? Como avaliar de forma eficiente os impactos pedagógicos dessa ferramenta? Existem regras para se produzir teatro científico? Essas são algumas questões que ainda estão sendo foco de estudos e que não possuem respostas fechadas dentro da literatura científica. Porém, no caso da Química, é possível abranger um variado leque de assuntos possíveis de serem representados de uma maneira interessante e agradável. As descobertas, as invenções, as próprias reações químicas, as aplicações dessa Ciência no cotidiano, as biografias dos químicos mais conceituados, são apenas alguns exemplos do vasto manancial de temas possíveis a serem dramatizados. O simples fato de serem executados durante a encenação de uma 
peça, algumas reações químicas de efeitos visuais atraentes e/ou divertidos, e que sejam representativas de fenômenos com os quais se convivem diariamente, pode alterar a ideia que as pessoas têm sobre essa área da Ciência. ${ }^{20}$

Com relação as dramaturgias no teatro científico, poucos estudos são relatados na literatura. Kerby ${ }^{21}$ cita alguns elementos da dramaturgia para motivar a aprendizagem de Ciência, contando histórias através de perguntas, envolvendo o público com seus personagens, utilizando metáforas e impressionando com elementos surpresa. O dramaturgo Gunderson ${ }^{22}$ enfatizou que é absolutamente essencial aprender ciência básica o suficiente para representá-la com precisão, caso contrário, toda peça pode fracassar. Isto mostra o quanto o teatro científico exige em termos de pesquisa por parte dos dramaturgos e dos atores envolvidos no processo.

$\mathrm{Na}$ verdade, o conceito de teatro científico é muito mais profundo e vem sendo construído e se consolidando ao longo dos últimos anos. Ele engloba espetáculos que ocorrem em museus, centros de ciências e/ou escolas, com a preocupação de abordar os temas científicos sob uma vertente pedagógica. Esse tipo de espetáculo teatral, que se destina a discutir a Ciência, encontra denominação em práticas teatrais tais como: o teatro de tese e o teatro didático. ${ }^{23} \mathrm{O}$ teatro científico é uma atividade que vem ganhando vulto no cenário brasileiro, entre as ações que se propõem a discutir a Ciência e a Tecnologia para além dos aspectos

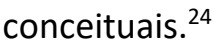

A metodologia de elaboração do teatro científico pode variar de forma diferente para cada grupo. Os espetáculos são adequados de acordo com o seu desenvolvimento, com etapas que vão desde a escolha do tema até a avaliação das peças. Por exemplo, o grupo da Seara da Ciência-UFC monta espetáculos envolvendo diferentes áreas de atuação, isso faz com que o processo metodológico varie a cada peça. O Show da Química-BA traz em suas peças experimentos científicos como proposta cênica, esse enfoque predomina também em outros grupos como Fanáticos da Química-UERN, Tubo de Ensaio-UECE. O projeto Olhares (UFSCar) surgiu em 2009 no Núcleo Ouroboros-SP e tem como proposta aliar inclusão e teatro científico, suas peças trazem atores com deficiência visual trabalhando com metodologias alternativas de divulgação.

No presente artigo, a fonte de inspiração na preparação das peças teve como ponto de partida a vivência artística dos seus autores no teatro convencional, além da consulta como material de apoio de filmes, literatura especializada na área de Química e documentários. Procurou-se, sempre que possível, incorporar episódios da História do Brasil nas peças, como no caso Lampião $e$ Maria Bonita em Busca da Química do Amor. $O$ acervo de textos e peças do grupo de teatro da Seara da Ciência, acumulados nos últimos 15 anos, foi outra fonte de orientação/inspiração na confeç̧ão das peças.

Assim sendo, o objetivo deste trabalho foi relatar as experiências obtidas através da montagem e da apresentação de seis peças envolvendo teatro científico. Apresenta-se aqui um levantamento dos resultados obtidos a partir de informações coletadas do público que assistiu as montagens cênicas, fruto de 3 anos de pesquisas e de divulgação científica teatral, em parceria com a Seara da Ciência - Universidade Federal do Ceará (UFC) e outras Instituições de Ensino Superior, verificando sobretudo os potenciais desdobramentos dessa estratégia metodológica no Ensino de Química.

\section{Metodologia}

Foram utilizadas duas abordagens diferentes na coleta de dados para posterior análise em face das peculiaridades das peças apresentadas. Para as peças $O$ Alquimista, Somos o que comemos? e Doutorado em Química do Amor, o método utilizado foi o da abordagem qualitativa, que visa obter dados descritivos mediante contato direto $\mathrm{e}$ 
interativo do pesquisador com o objeto de estudo. O foco da atenção foi voltado para o significado que as pessoas dão as coisas e as situações. ${ }^{25} \mathrm{~A}$ coleta de dados foi realizada através de questionários que continham perguntas sobre: (1) A proposta cênica da peça; (2) Ao conteúdo científico; (3) A dramaturgia e (4) A junção Arte e Ciência. $O$ questionário também solicitava que fosse dado uma nota ( 0 a 10) para a peça como um todo e, uma última pergunta sobre comentários gerais sobre a peça (críticas, sugestões, elogios, etc.).

Já para as peças Os vingadores químicos, Lampião e Maria Bonita em busca da Química do amor e A Liga da Ciência que foram apresentadas em locais abertos e por outros grupos de teatro, utilizou-se como dados as observações das impressões e diálogos com a plateia, composta principalmente pelo público estudantil. Essas discussões aconteciam imediatamente após a apresentação e contava com a participação de todos os atores envolvidos. A análise qualitativa foi baseada na metodologia de Análise de Conteúdo. ${ }^{26}$ As respostas foram agrupadas em conjuntos distintos através de um processo de diferenciação e reagrupamento, sendo, então, categorizadas segundo critérios semânticos. A categorização deste estudo foi feita a partir da classificação analógica e progressiva dos elementos constituintes das respostas, seguindo os critérios de exclusão mútua, homogeneidade, pertinência, objetividade/fidelidade e produtividade.

\subsection{A Montagem das Peças}

As peças A Liga da Ciência (1), O Alquimista (2), Somos o que Comemos? (3), Lampião e Maria Bonita em Busca da Química do Amor (4), Os Vingadores Químicos (5) e Doutorado em Química do Amor (6), foram montadas em parceira com o grupo de Teatro Científico da Seara da Ciência-UFC. A peça Os Vingadores Químicos recebeu duas diferentes montagens, uma em parceria com o grupo Fanáticos da Química, da Universidade do Estado do Rio Grande do Norte (UERN) e outra com o grupo LetraFísicoQuímic da Universidade Estadual do Maranhão (UEMA).

Para a dramaturgia das peças foi trabalhado uma metodologia que compreendeu a Ciência sob uma perspectiva contextualizada e ao mesmo tempo contemporânea. Os textos foram criados sempre aliando o humor à situações e temas cotidianos, uma vez que são mais bem recebidas pelo público alvo, os alunos da Educação Básica.

As sinopses das peças e os comentários a respeito da idealização e da confecção das mesmas encontram-se sintetizadas a seguir:

1. A Liga da Ciência: A peça traz um confronto, através de experimentos, entre $O$ vilão Mercúrio, que tenta usar os seus conhecimentos para destruir a Seara, a Liga da Ciência e os Super-heróis Quimicoman, Hidrogênia, Nitrogênia e Oxigênia. O tempo estimado da peça era de 30 minutos.

A peça foi montada em 2013 e a fonte inicial de inspiração foi o filme $A$ Liga da Justiça, cujos protagonistas são os superheróis clássicos. Antes da peça chegar aos palcos foram necessários cerca de três meses de ensaios com o elenco composto por 5 atores, todos graduandos da UFC, três deles do curso de Licenciatura em Química. Uma pesquisa criteriosa foi realizada no sentido de que os experimentos químicos demonstrados criassem um forte apelo visual. Os experimentos foram preparados e testados no Laboratório de Química da Seara da Ciência, e o elenco passou por um treinamento específico para demonstrar em cena os experimentos, sem nenhum risco físico para os atores e/ou espectadores. Os experimentos químicos explorados na peça foram: liberação de energia, decomposição da água oxigenada, indicadores ácido-base, reação de polimerização do poliuretano, reações de complexação, reações de metais em água, reação de dissolução e liberação de 
gás.

2. O Alquimista: Um cientista famoso explica o surgimento da Química, desde a alquimia até os tempos modernos, utilizando vários experimentos científicos: reações com mudança de cor; liberação de gás; formação de precipitado; liberação de energia. A peça usa o conhecimento do alquimista, convencido de que encontrou o elixir da vida longa, e por isso pode conhecer grandes cientistas, como Paracelso (1493 - 1541), Lavoisier (1743 - 1794), Dalton (1766 1844), Mendeleyev (1834 - 1907) e Marie Curie (1867 - 1934), apresentando ao público suas contribuições para o mundo da ciência. O tempo estimado da peça era de 40 minutos.
A peça é um monólogo que traz para o palco a História da Química. A montagem cênica foi inspirada na obra Mundos Invisíveis - Da Alquimia a Física de Partículas de Marcelo Gleiser. Na construção do texto se deu no sentido de seguir uma sequência cronológica da História da Química, desde a biografia até as contribuições dos primeiros grandes cientistas. Ela foi montada para atingir o público de modo geral, em especial aos estudantes do nível fundamental e médio. A peça foi composta por 11 experimentos envolvendo liberação de gás, mudança de cor, reações de oxirredução reação de precipitação e liberação de energia. A Figura 1 ilustra o cartaz de divulgação da peça.

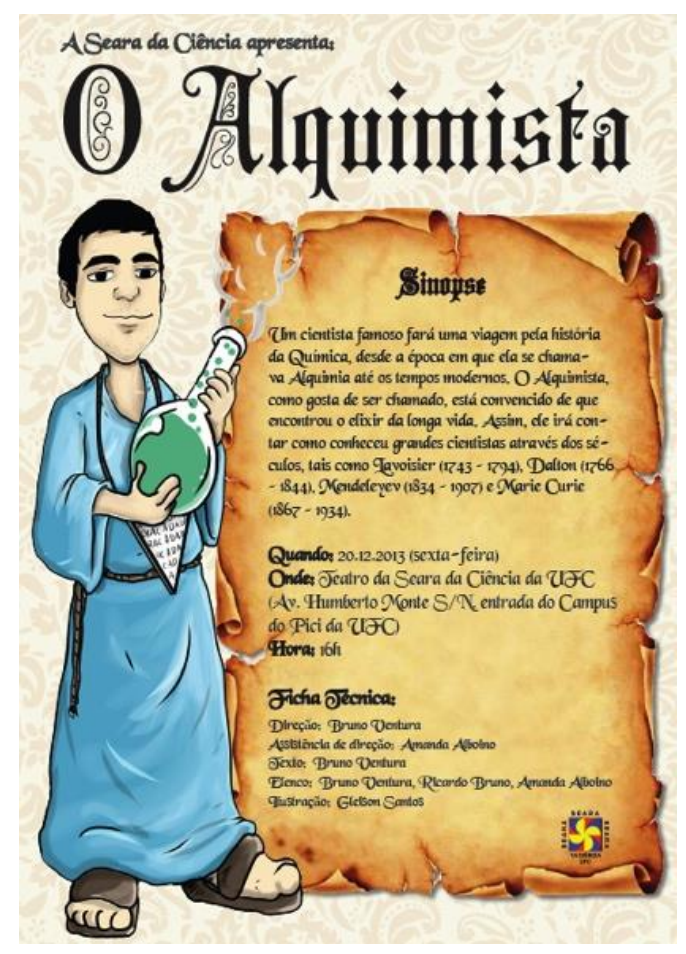

Figura 1. Cartaz de divulgação da peça $O$ Alquimista. Fonte: Autores

3. Somos o que Comemos?: Dramaturgia montada sob a ótica do teatro social, composta por três atos abordando a temática da Educação Alimentar. No 1o ato, um exobeso descreve a química dos alimentos, $o$ bullying sofrido, os preconceitos da sociedade sobre os obesos e o dilema entre comer ou não comer. Essas são as questões colocadas em cena com humor, utilizando a estética do teatro documentário. No $2 \stackrel{0}{a}$ ato, um "nutricionista maluco" mostra para seu paciente (personagem invisível) o quanto de sal, açúcar e gorduras são encontrados nos alimentos industrializados. No 3ㅇ ato 
acontece um programa informativo, com perguntas e respostas, abordando dicas de educação alimentar, denominado de Encontro com Letícia Salada. O tempo estimado da peça era de 45 minutos.

A peça é um monólogo abordando a Química dos alimentos na temática social da obesidade infantil. Foi necessário uma ampla pesquisa em livros e artigos especializados na área de alimentos, bem como documentários sobre a questão da obesidade. A peça trouxe para os palcos a Ciência por trás dos alimentos industrializados, assim como definições importantes como: colesterol, glúten, proteínas, carboidratos, lipídios, alimentos industrializados, etc. Houve também uma pesquisa em rótulos de alimentos industrializados mais consumidos pela sociedade atual, observando as quantidades de açúcar, sal e gorduras, bem como curiosidades e mitos a respeito da educação alimentar, focando a abordagem com muito humor, música, projeções e vídeos. O monólogo foi ensaiado por três meses.

\section{Lampião e Maria Bonita em Busca da}

Química do Amor: A estória se passa em dois ambientes: Na rodoviária e na Caatinga. Maria Bonita e Lampião estão passando por uma crise conjugal e acabam "lavando a roupa suja em cena". No transcorrer da peça eles passam a ser cobaias de uma cientista retirante, que irá fazer com que o casal experimente as substâncias químicas do amor (norepinefrina, feniletilamina, dopamina) para reacender a chama da paixão. A duração da peça é de 45 minutos.

Essa peça uniu Ciência e História do Brasil. Para a construção do texto foi necessário consultar livros e documentários sobre o cangaço, Lampião, Maria Bonita e o contexto sócio histórico da época, além da pesquisa sobre os efeitos das substâncias ditas como do amor no organismo humano. A montagem do espetáculo durou três meses. O elenco contou com 6 atores, todos graduandos da UFC e um músico profissional. Foram inseridas na peça músicas inéditas criadas pelo grupo da Seara. O figurino foi confeccionado buscando ser o mais fidedigno possível a época do cangaço, Figura 2. A proposta foi adaptar o texto à espetáculos de teatro de rua, facilitando apresentações em locais abertos.

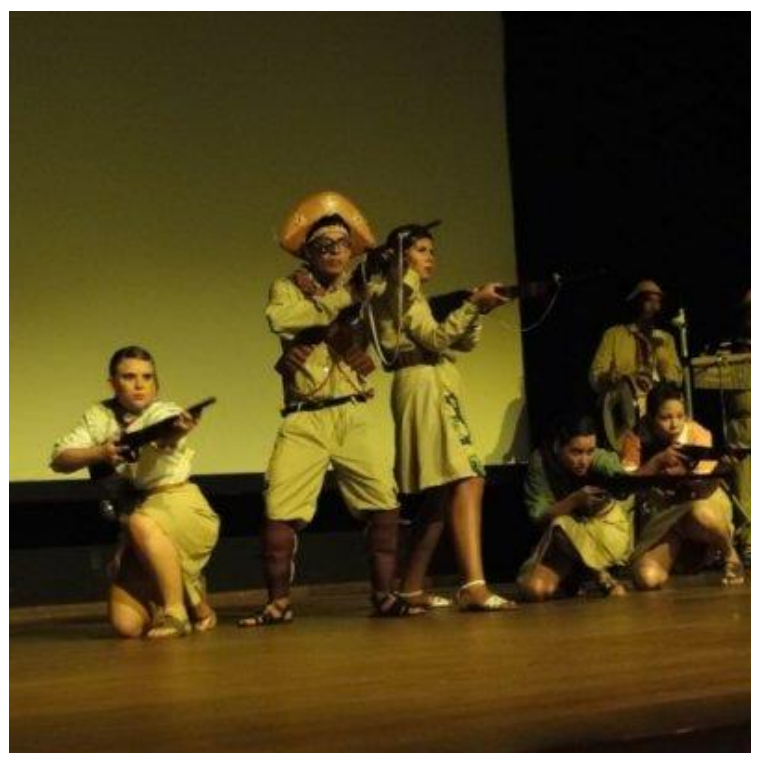

Figura 2. Cena da peça Lampião e Maria Bonita em Busca da Química do Amor. Fonte: https://www.youtube.com/watch?v=sBni YOfE7M 
5. Os Vingadores Químicos: $O$ isótopo Trítio $\left({ }^{3} \mathrm{H}\right)$ é uma arma poderosa do vilão Urânio que pretende destruir o mundo periódico. Para impedir que esta tragédia ocorra três heróis se unem: Ferro, Tório e Amerício. Na caça ao vilão eles encontrarão pelo caminho vários elementos químicos, $e$ com a ajuda destes travarão uma batalha épica na busca pela estabilidade do mundo periódico. O tempo estimado da peça era de 50 minutos.

A peça é uma paródia do filme Os Vingadores, que reúne diversos super-heróis. Para ser colocado na dramaturgia da peça foram pesquisados figurinos, adereços e as características dos super-heróis como: Capitão América, Homem de Ferro e Thor, intitulados na peça por Amerício, Ferro e Tório, respectivamente. $\mathrm{O}$ assunto abordado foi a tabela periódica e suas propriedades. A montagem da peça foi executada por dois grupos: os Fanáticos da Química-UERN, que adaptou experimentos na proposta cênica com 10 atores (Figura 3) e o Letra FísicoQuimic-UEMA que produziu uma versão fiel ao texto original, contando com 12 atores.

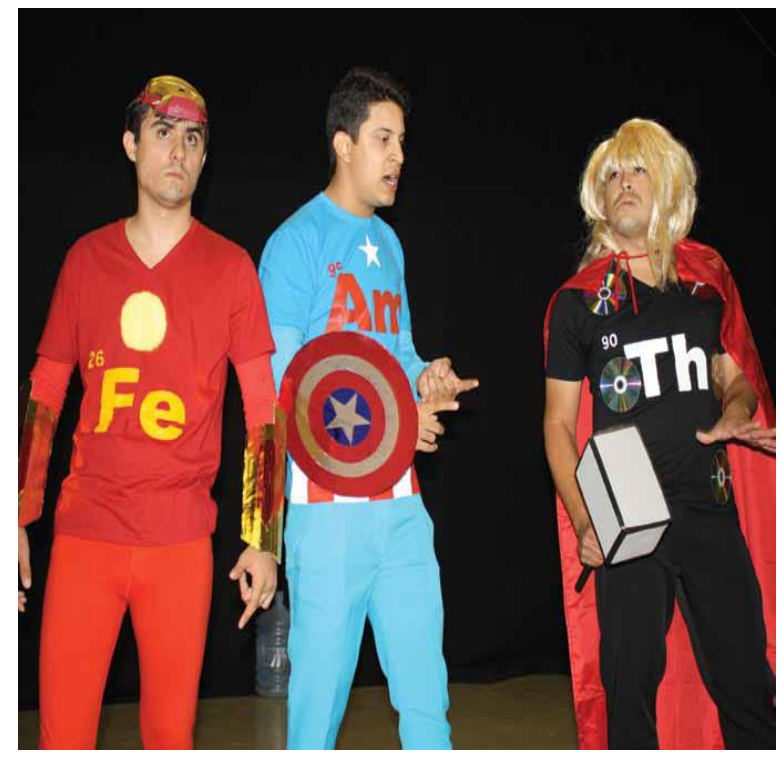

Figura 3. Cena da peça Os Vingadores Químicos. Fonte:

https://www.youtube.com/watch?v=65Zxvtodm w

6. Doutorado em Química do amor: Um químico defendeu sua tese de doutorado apresentando as fases do amor e suas explicações científicas usando como tema sua própria vida amorosa, através das mulheres com as quais se envolveu emocionalmente. $A$ peça é na verdade um diálogo com o público, marcado pelo drama, humor e trilha musical. Poesia, medo, solidão são também ingredientes do espetáculo que conta estórias que se encontram e se confundem, num misto de realidade e utopia lúdica, o sonho de ser feliz impactado por vezes pela dura realidade. O tempo estimado da peça era de 50 minutos.

As moléculas do amor foram apresentadas de uma forma científica e ao mesmo tempo cômica e dramática. A peça questiona o teatro como forma de representação do real e rompe a ilusão dramática. A montagem do espetáculo ocorreu através de 4 meses de ensaios, neste período foram confeccionados os cenários e adereços da peça, bem como a sonoplastia, que contou com playbacks de músicas populares brasileiras gravadas em estúdio. 


\section{Resultados e Discussão}

Como já mencionado, todos os relatos aqui apresentados foram baseados na experiência obtida durante 3 anos de pesquisas e divulgação científica teatral, tanto na preparação e apresentação das peças, quanto com as informações coletadas do público espectador (estudantes e professores). O levantamento realizado compilou dados como o ano de elaboração das peças, o número e local das apresentações, assim como o público estimado, Tabela 1.

Tabela 1: Título das peças, ano de criação, número de apresentações, público estimado e locais de apresentação.

\begin{tabular}{|c|c|c|c|c|}
\hline Peça & $\begin{array}{l}\text { Ano de } \\
\text { criação }\end{array}$ & $\begin{array}{c}\mathbf{N}^{\circ} \text { de } \\
\text { Apresentações }\end{array}$ & $\begin{array}{l}\text { Público } \\
\text { estimado }\end{array}$ & Locais de Apresentação \\
\hline A Liga da Ciência & 2013 & 3 & 1000 & $\begin{array}{l}\text { Centro de Cultura e Arte de } \\
\text { Fortaleza-CE (CUCA), } 01 \text { escola } \\
\text { pública de Horizonte-CE e } 01 \text { escola } \\
\text { pública de Fortaleza. }\end{array}$ \\
\hline O Alquimista & 2013 & 2 & 100 & Seara da Ciência - UFC \\
\hline $\begin{array}{l}\text { Somos o que } \\
\text { comemos? } \\
\text { Educação } \\
\text { alimentar em } 3 \\
\text { atos }\end{array}$ & 2014 & 80 & 6000 & $\begin{array}{l}\text { Seara da Ciência-UFC; } 07 \text { escolas } \\
\text { públicas e } 1 \text { particular de Fortaleza- } \\
\text { CE; } 02 \text { Instituições de Ensino } \\
\text { Superior (IFCE, UECE); Biblioteca } \\
\text { municipal de Bonfim (RR); } 01 \text { escola } \\
\text { municipal de Bonfim (RR); } 01 \text { escola } \\
\text { de Lethen (Guiana) e } 02 \text { centros } \\
\text { educacionais de menores infratores } \\
\text { de Fortaleza-CE }\end{array}$ \\
\hline $\begin{array}{l}\text { Lampião e Maria } \\
\text { Bonita em Busca } \\
\text { da Química do } \\
\text { amor }^{(\text {a) }}\end{array}$ & 2014 & 30 & 2000 & $\begin{array}{c}\text { Seara da Ciência-UFC; VIII Festival } \\
\text { Nacional de Teatro Científico - São } \\
\text { Carlos /SP; Centro de Cultura e Arte } \\
\text { de Fortaleza-CE; X Festival de Teatro } \\
\text { de Fortaleza-CE; Festival Fartura } \\
\text { Fortaleza-CE; Centro de Educação à } \\
\text { Distância em Sobral-CE; SESC-CE e } \\
\text { Centro Cultural Dragão do Mar-CE }\end{array}$ \\
\hline $\begin{array}{l}\text { Os vingadores } \\
\text { químicos }\end{array}$ & 2014 & 15 & 1000 & $\begin{array}{l}\text { VIII Festival Nacional de Teatro } \\
\text { Científico - São Carlos / SP; } 10 \\
\text { escolas públicas de Caxias-MA; } 02 \\
\text { escolas públicas de Mossoró-RN e } \\
\text { SESC-MA }\end{array}$ \\
\hline $\begin{array}{l}\text { Doutorado em } \\
\text { Química do amor }\end{array}$ & 2015 & 13 & 500 & $\begin{array}{l}\text { Fórum da cidade de Bonfim-RR; IFCE } \\
\text { - Camocim-CE; Seara da Ciência- } \\
\text { UFC; } 01 \text { escola pública de Pajuçara- } \\
\text { CE; Camocim-CE e Faculdade de } \\
\text { Educação da UFC-CE }\end{array}$ \\
\hline
\end{tabular}

(a) Peça em cartaz. Fonte: Autores 
As peças tiveram seu início em 2013, com a peça A Liga da Ciência. Foram 3 apresentações com um público estimado de 1000 espectadores. O forte impacto visual dos experimentos apresentados no palco associados ao elemento surpresa, assim como os figurinos exagerados e inovadores dos personagens, todos conduzidos sob um viés cômico; garantiram o sucesso da montagem teatral e cumpriram o objetivo de impressionar o público e aguçar os sentidos dos espectadores.

No transcorrer da peça, os atores usavam falas e gestos específicos, atrelado a execução de experimentos, os quais conduziam os estudantes a refletirem sobre certos fenômenos químicos, como por exemplo, a elevada reatividade do metal sódio quando em contato com a água, tendo como resultado a ignição do hidrogênio, com acentuado aumento de temperatura.

Após a apresentação, durante os diálogos com a plateia, era muito comum o público estudantil se aproximar dos atores, buscando respostas as indagações acerca dos experimentos químicos demonstrados na peça. Nesse e em outros momentos foi nítido que o espetáculo encantou e aguçou a curiosidade dos alunos.

De acordo com Medina, ${ }^{27}$ através do teatro científico é possível atrair o público para assuntos científicos, com as constantes dúvidas e reflexões, cada vez mais presentes nas preocupações de todos enquanto indivíduos. Deste modo, ele deve ser encarado como uma possibilidade de cativar o público, além de constituir uma agradável ferramenta de ensino.

A segunda peça, $O$ Alquimista, também foi escrita e produzida em 2013 e apresentada no teatro da Seara da Ciência-UFC para um público de cerca de 100 alunos da Educação Básica. Também neste caso, foi observada uma forte interação entre o público e o ator da peça, ao término da apresentação. Nesse caso, 50 alunos responderam ao questionário, estes deram uma nota média de 9,5 ao espetáculo, levando em consideração a dramaturgia, o cenário, os adereços e a atuação. Foi possível obter considerações bastante interessantes a respeito da opinião dos alunos:

A peça ajuda a inserir conteúdos a serem ensinados no cotidiano dos alunos.

A peça foi perfeita, bem elaborada, teve um bom conteúdo e não faltou uma pitada de humor.

Foi bastante proveitoso aprender mais sobre a História da Química. Deveria ser apresentada mais vezes.

Esses e muitos outros comentários positivos mostraram que a proposta cênica teve boa aceitação. A grande maioria respondeu que o texto era acessível, esclarecedor para pessoas de qualquer idade e que conseguiu ser lúdico e científico ao mesmo tempo. Resultado semelhante foi obtido por Saraiva ${ }^{20}$ quando questionou alunos da Educação Básica que assistiram a peça Oxigênio, a maioria dos alunos manifestou interesse pelo teatro científico enquanto estratégia de aprendizagem de forma lúdica.

Mais do que encantar o público pela Ciência, o teatro científico visa, acima de tudo, provocar o público e fazê-lo refletir sobre o conhecimento apresentado. ${ }^{28} \mathrm{O}$ próprio texto da peça apresenta elementos que buscam atrair a atenção e despertar a curiosidade dos alunos, tendo a ludicidade como tônica da sua proposta, ao mesmo tempo em que se brinca com o próprio texto, como pode ser observado no trecho abaixo:

ALQUIMISTA: Para começar, gostaria de perguntar se alguém da plateia sabe o que é Alquimia $e$ o que os alquimistas queriam alcançar? Vocês não sabem?! (Neste momento, aguardou-se a resposta de alguns espectadores). Alquimia foi um período que se deu entre 500 e 1500, na Idade Média, era 
constituída de homens que acreditavam que usando o poder do fogo poderiam transformar metais baratos em ouro, eles buscavam o "elixir da longa vida", quem conseguisse realizar essas descobertas viveriam por muitos anos. $E$ confesso a todos que este último sonho dos alquimistas eu consegui realizar. Isso mesmo que vocês ouviram: eu sou um alquimista e nasci na Idade Média. De lá para cá, conheci muitos cientistas, inclusive os ajudei nas suas pesquisas.

O trecho ilustra como o teatro pode despertar o interesse dos alunos através da interação com o público. Dessa forma, o teatro científico pode propor maneiras diferentes de estimular a aprendizagem de conteúdos específicos. De acordo com Moreira e Marandino ${ }^{28}$ os textos teatrais desenvolvidos pela Seara da Ciência visam veicular Ciência de forma simples, lúdica e agradável, na forma de diálogos bem humorados, nos quais é perceptível a preocupação em privilegiar conhecimentos científicos fundamentais.

A peça Somos o que Comemos? foi encenada de maio a dezembro de 2014, chegando a ser apresentada 80 vezes, totalizando um público em torno de 6000 espectadores, onde 2000 destes responderam o questionário após a peça. Foram 60 sessões no teatro da Seara da Ciência-UFC e outras 20 em diferentes instituições de ensino de Fortaleza e região metropolitana.

Essa foi a peça de maior sucesso, refletido nos inúmeros convites para apresentações, inclusive nos dias atuais, pelos comentários do público e pelo resultado dos questionários aplicados, recebendo do público uma média de 9,7. A proposta cênica tocou em um problema social, a obesidade no mundo atual e suas causas e consequências, e a plateia se identificou com a problemática. Isso mostra a importância de colocar a Ciência sob uma forma contextualizada para os estudantes, visto que na peça, especificamente no seu segundo ato, aborda a questão da obesidade infantil.
De fato, fora do contexto do aluno, a Química normalmente não é compreendida por este, que tem muita dificuldade para perceber as relações com a sua vida e/ou com a sociedade. ${ }^{29}$ Além disso, a peça também trouxe conceitos de Bioquímica, mostrando além de um texto contextualizado, a interdisciplinaridade como ferramenta de integração entre duas grandes áreas.

A análise dos questionários aplicados nesta peça mostrou que $80 \%$ do público concordou que o texto era interessante e bem escrito:

Ótima proposta do conteúdo, visto que este engloba a sociedade em geral e o seu modo de agir e de se alimentar de maneira errada. A peça é reflexiva e crítica.

Houve momentos que fiquei assustado com a quantidade de açúcar e óleo nos alimentos industrializados que o 20 ato da peça apresentou.

A peça faz refletirmos a partir de uma visão lúdica do quanto nos alimentamos de forma inadequada.

É um assunto super importante para evitar problemas de saúde e proporcionar a nossa educação alimentar.

A peça Lampião e Maria Bonita em Busca da Química do Amor teve sua estreia no Festival Nacional de Teatro Científico (VIII Ciência em Cena, São Carlos - SP, 2014). Nesta ocasião, a peça foi agraciada com o Prêmio de melhor espetáculo no festival, que contou com a participação de diversos grupos do Brasil e de Portugal. Seu sucesso é incontestável, desde 2014 até os dias atuais ela ainda está em cartaz, incluindo apresentações semanais na Seara da CiênciaUFC e em festivais de teatro da cidade de 
Fortaleza-CE. A peça trouxe conceitos envolvendo a Química, Bioquímica e Farmacologia, ampliando a capacidade do aluno de vivenciar múltiplas linguagens e novas tecnologias, fazendo com que seu conhecimento passe a ser global e não mais fragmentado, como normalmente chega até ele.

O teatro pode ser considerado uma grande ferramenta didática no processo de ensino-aprendizagem, já que traz um novo olhar para o saber científico no ambiente escolar. Além disso, com o teatro é possível disseminar uma temática, bem como provocar novas ideias e reflexões, possibilitando ganhos, tanto individuais quanto coletivos. ${ }^{30}$

A peça Os Vingadores Químicos foi montada, inicialmente, pelo grupo Fanáticos da Química-UERN, sua estreia aconteceu no VIII Festival de Ciência em Cena, e foi premiada como o segundo melhor espetáculo do evento. O sucesso da peça fez com que a mesma tenha recebido diversos convites para apresentação em escolas e Instituições de Ensino Superior do estado do Rio Grande do Norte. O texto também foi cedido para o grupo maranhense LetraFísicoQuímic-UEMA, que realizou várias apresentações. Houve um grande interesse por parte dos professores da Educação Básica em relação a peça, uma das maiores justificativas está no fato dela ser educativa e lúdica ao mesmo tempo. Como a proposta cênica é sobre a tabela periódica, são abordadas aplicações envolvendo os elementos químicos e conceitos sobre a Química Inorgânica, como nesta passagem:

AMERÍCIO: Ei mocinho quem é você?

HIDROGÊNIO: Eu sou o mais leve dos elementos, sou gasoso e sou o mais abundante do universo, meu nome é Hidrogênio!

TÓRIO: Valha que nome mais estranho!

HIDROGÊNIO: Estranho é a mãe! Meu nome é o mais bonito de todos aqui e foi dado por Lavoisier em 1783.
FERRO: Já que você é o tal, me diz aí pra que tu serve?

HIDROGÊNIO: Vejamos, eu sou muito consumido em diversos processos químicos industriais. Ah e junto com o elemento Oxigênio formamos a água, que é essencial a vida e pode ser encontrado em abundância em três estados físicos.

AMERÍcIO: Eu só não entendi por que você está dentro deste foguete $e$ veio correndo?

HIDROGÊNIO: Ah meu caro! Tenho muitas aplicações, sou usado como combustível de foguetes! Sou fonte de energia!

A peça Doutorado em Química do Amor teve sua estreia no fórum da cidade de Bonfim -RR, evento educacional bilíngue Brasil-Guiana Inglesa, em 2015. Após sua estreia, o espetáculo subiu aos palcos mais 12 vezes, totalizando um público estimado em 500 espectadores, com 300 respondentes do questionário, entre estudantes da Educação Básica e professores. Os depoimentos apontaram que a apresentação foi dinâmica, lúdica, atraente contextualizada e recebeu uma nota média de 9,6 pelo público. A grande maioria dos respondentes (90\%) concordou que a proposta cênica conseguiu equilibrar os elementos artísticos sem deixar o conhecimento científico de lado:

A peça apresentada ficou bem equilibrada entre a Química e o Teatro, assim não dá pra confundir com aula em cima do palco, muito menos um espetáculo sem elementos científicos.

Foi muito bom o espetáculo, pois mostra o amor de uma forma diferenciada, ou seja, a química do amor em nossas vidas.

A química do amor é um assunto que consegue mostrar a aplicação dessa ciência 
no cotidiano e a peça só veio unir isso com Ciência e Arte.

A parte científica ficou evidenciada através do cenário, que tinha como pano de fundo as representações das moléculas do amor, projetadas no palco quando eram mencionadas na peça, como no trecho a seguir:

ATOR: Foi com Daniela que tive minha primeira experiência de Química do amor. Foi aí que entrou em ação a Norepinefrina, um estimulante natural do cérebro que está associado à exaltação, euforia, falta de sono e de apetite. É nessa hora que as mãos suam, a respiração falha, é difícil pensar com clareza, dar aquele friozinho no estômago. Ah! E quando o coração bate acelerado, é por que a norepinefrina está atuando.

A parte lúdica da proposta ficou marcada por músicas da MPB interpretadas pelo ator, que arrancou de forma rápida muitos aplausos da plateia. $O$ espetáculo chamou atenção por trazer uma apresentação de uma Tese de Doutorado, apresentada informalmente. Um comentário relevante que foi destacado por um profissional do meio artístico coincide com a proposta inicial do espetáculo que era justamente trazer para os palcos algo que se fala dos bastidores e do próprio teatro ${ }^{31}$, unindo com a parte científica das moléculas do amor, conforme demonstrado a seguir:

Interessante e mágico como o ator consegue controlar tudo no palco, as músicas, os adereços cênicos, os slides, os vídeos $e$ ainda expõe os bastidores da peça na cara do público.

Por todas as experiências aqui relatadas, verificamos que o teatro científico pode ser encarado como uma ferramenta pedagógica que trabalha conceitos científicos presentes no cotidiano dos alunos de forma lúdica, interativa, prazerosa, contextualizada e, na maioria das peças aqui mencionadas, com uma forte característica interdisciplinar na maioria dos casos, o que possibilitou aos espectadores entenderem a realidade na qual estão inseridos e as transformações que ocorrem no seu próprio corpo, na natureza e no seu entorno.

Os autores compreendem e tem muito claro as dificuldades encontradas no transcorrer do caminho, o objetivo na divulgação dos resultados aqui apresentados não é fazer com que cada professor deva ser um ator tão pouco dê início a escrita e montagens cênicas. O que se deseja é mostrar a importância do teatro cientifico no processo de construção do conhecimento e como ele pode ser apresentado através de uma ferramenta de divulgação científica que encante e aguce o interesse dos alunos, podendo vir a ser um catalisador da alfabetização científica.

Muito embora Arte e Ciência sejam consideradas pela maioria das pessoas como áreas distintas, a combinação de ambas pode promover a educação científica da população em geral, uma vez que as manifestações artísticas têm o poder de despertar o interesse, gerar reflexões e provocar sensações variadas no público, e podem servir de veículo para popularização da ciência. Desta forma, cabe ao professor saber o momento exato em que seus alunos devem entrar em contato com o teatro científico, como forma de motivá-los a buscar o conhecimento embutido em cada espetáculo e na aprendizagem da Química ensinada na escola. De acordo com as respostas recebidas, o teatro científico como recurso didático abre novos caminhos para a prática docente.

\section{Conclusões}

De acordo com os dados coletados, as peças apresentadas neste trabalho tiveram 
grande aceitação do público, ficando evidenciado pelo quantitativo de apresentações, convites e premiações recebidas. Diversos conceitos de Química puderam ser ilustrados/explorados através das propostas teatrais, impactando os expectadores com muito humor e ousadia.

As peças premiadas mostraram que as dramaturgias foram bem desenvolvidas em suas metodologias e com ótima aceitação pelo público de teatro científico, o que fortaleceu os espetáculos e os fizeram ganhar grandes repercussões, como por exemplo, um mesmo texto sendo usado por dois grupos diferentes e de instituições distintas.

A plateia, de modo geral, expôs uma visão positiva sobre o teatro científico para divulgação da Química, utilizado como ferramenta para estimular a aprendizagem de conceitos químicos e saberes pedagógicos e disciplinares, assim como uma alternativa lúdica no ensino de Química.

As peças foram encenadas em diversos ambientes formal e informal de ensino. Elas foram elaboradas para serem encenadas em teatros, auditórios, salas de aula, quadra esportivas, em praças e logradouros públicos, entre outros. Isto foi assim pensado para facilitar suas reproduções e incentivar professores a incluir em sua prática docente o teatro científico, seja atuando ou levando seus alunos a espetáculos como forma de motivá-los para o aprendizado da Química.

Os resultados apresentados apontaram que a criação, produção e encenação teatral de cunho científico deve ser sempre incentivada e continuada, a união entre a Arte e a Ciência é benéfica para o ensino e contribui para a popularização e divulgação do conhecimento científico.

Por fim, cabe ressaltar que as produções de dramaturgias de teatro científico ainda são pouco divulgadas na literatura. 0 mesmo ocorre nos diversos grupos que atualmente fazem teatro científico no Brasil, seu crescimento não acompanha o número de relatos de experiência desses grupos na literatura, há uma carência das publicações destas experiências em revistas especializadas.

\section{Agradecimentos}

Ao CNPq, CAPES e a FUNCAP pela apoio financeiro. Aos grupos de teatro científico da Seara da Ciência-UFC, Fanáticos da QuímicaUERN e Letra FísicoQuimic-UEMA. A toda a equipe de atores, diretores e técnicos que fizeram parte das peças. A todos os espaços cedidos para que as peças fossem encenadas. A Seara da Ciência pela parceria e espaço concedido para realização das pesquisas e encenações.

\section{Referências Bibliográficas}

${ }^{1}$ Rocha, L. D. S.; Goes, H. B. O. Como melhorar as aulas de Química para Ensino Médio sob a óptica dos alunos de colégios particulares da região metropolitana do Rio de Janeiro (RJ). Anais do XVIII Encontro Nacional de Ensino de Química - ENEQ, Florianópolis, Brasil, 2016. [Link]

2 Portz, L. G.; Eichler, M. L. Uso de Jogos Digitais no Ensino de Química: um Super Trunfo sobre a Tabela Periódica. Resumo do 33 Encontro de Debates sobre o Ensino de Química, Unijuí, Brasil, 2013. [Link]

${ }^{3}$ Gama E. G.; Silva, K. A.; Sousa, M. H. Cirquim: Motivando o interesse pela Química. Enciclopédia Biosfera 2015, 11, 21. [Link]

${ }^{4}$ Neto, H. D. S. M.; Pinheiro, B. C. S.; Roque, N. F. Improvisações Teatrais no Ensino de Química: Interface entre Teatro e Ciência na Sala de Aula. Química Nova na escola 2013, 35, 100. [Link]

${ }^{5}$ Lima, J. O. G.; Barbosa, L. K. A. O Ensino de Química na Concepção dos Alunos do Ensino Fundamental: algumas Reflexões. Ex@tas Online 2015, 6, 33. [Link]

${ }^{6}$ Queiroz, B. V.; Diógenes; F. J. M. O.; Fechine, P. B. A. Jogo das Soluções: Simulando um Experimento no Laboratório de Química Utilizando uma Proposta Lúdica Para o Ensino Médio. Revista Virtual de Química 2016, 8, 2042. [CrossRef] 
${ }^{7}$ Pedrolo. C. R; Serpa, D.; Domingues, F.; Mello, N.; Wippel, S. S.; Silva, A. M. Aprender Química brincando: Uma Gincana no Colégio Coronel Pilar de Santa Maria. Anais do 33응 Encontro de Debates sobre o Ensino de Química. Unijuí, Brasil, 2013. [Link]

${ }^{8}$ Oliveira, J. S.; Soares, M. H. F. B.; Vaz, W. F. Banco Químico: um Jogo de Tabuleiro, Cartas, Dados, Compras e Vendas para o Ensino do Conceito de Soluções. Química Nova na Escola 2015, 37, 285. [CrossRef]

${ }^{9}$ Campos, L. M. L; Bortoloto, T. M.; Felicio, A. K. C. A Produção de Jogos Didáticos para o Ensino de Ciências e Biologia: Uma Proposta para Favorecer a Aprendizagem. 2008. Disponível

em:<www.unesp.br/prograd/PDFNE2002/apr oducao dejogos.pdf $>$ Acesso em 26 de abril de 2016.

${ }^{10}$ Cunha, M. B. Jogos no Ensino de Química: Considerações Teóricas para sua Utilização em Sala de Aula. Química Nova na Escola 2012, 34, 92. [Link]

${ }^{11}$ Soares, M. H. F. B. Jogos para o Ensino de Química: Teoria, Métodos e Aplicações. Ex Libris, Guarapari-ES, 2008.

${ }^{12}$ Silveira, M. P., Kiouranis, M. M. A Música e o Ensino de Química. Química Nova na Escola 2008, 28, 28. [Link]

${ }^{13}$ Sousa Júnior, F. S. Química em cena: Uma Proposta para Formação Inicial de Professores de Química. 2015. 241f. Tese Doutorado em Química: - Programa de PósGraduação em Química, Universidade Federal do Rio Grande do Norte - UFRN, 2015.

${ }^{14}$ Robaina, J. V. L. Química Através do Lúdico: Brincando e Aprendendo. Ed. ULBRA: Canoas, RS, 2008.

${ }^{15}$ Batista, D. N.; Ribeiro, E. M. L.; Pereira, A.; Souto, A.; Rodrigues, R. O Teatro científico no Brasil e o Ensino de Física. Anais do XVIII Simpósio Nacional de Ensino de Física, Vitória, Brasil, 2009. [Link]

${ }^{16}$ Silveira, A. F.; Silva, A. P. B.; Filho, A. R. A Divulgação da Ciência Através do Teatro: Um Estudo em Copenhague de Michael Frayn. Anais do VII Encontro Nacional de Pesquisa em Educação em Ciência (ENPEC), Florianópolis, Brasil, 2009. [Link]
17 Sousa Júnior, F. S.; Hussein, F. R. G. S.; Souza, L.; Oliveira, Ó. A.; Malcher, G. T. O Teatro Científico na Formação Inicial de Professores de Química: Experiência do Grupo Química em Cena. IX Congreso Internacional sobre Investigación en Didáctica de las Ciencias, Girona, Espanha, 2013. [Link]

${ }^{18}$ Nunes, C. T. S.; Lima, K. S.; Santos, M. L.; Silva, E. L. Cultura, Ciência e Teatro: Uma Tríade Possível para o Ensino de Química. Scientia Plena 2014, 10, 087206-1. [Link]

${ }^{19}$ Lupetti, K. O.; Serafim, T.; Pugliere, T.; Lima, L.; Macedo, A., Rodrigues, C.; Pereira, T.; Gromboni, M.; Moura, A.; Margues, C. Ciência em cena: teatro e divulgação científica. Anais do XIV Encontro Nacional de Ensino de Química (XIV ENEQ), Curitiba, Brasil, 2008. [Link]

${ }^{20}$ Saraiva, C. C. Teatro científico e ensino da química. 2007. 171f. Dissertação (Mestrado em Química) - Programa de Pós-Graduação em Química, Universidade do Porto, Porto, Portugal, 2007.

${ }^{21}$ Kerby, H. W.; Cantor, J.; Weiland, M. J.; Babiarz, C. L.; Kerby, A. W. Fusion Science Theater Presents The Amazing Chemical Circus: A New Model of Outreach That Uses Theater To Engage Children in Learning. Journal of Chemical Education 2010, 87, 1024. [CrossRef]

$22{ }^{22}$ Gunderson, L. Science plays come of age. The Scientist. 2006. Disponível em: < http://www.thescientist.com/?articles.view/articleNo/24219 /title/Science-plays-come-of-age/>. Acessado em: 6 setembro 2016.

${ }^{23}$ Pavis, P. Dicionário de teatro. Ed. Perspectiva: São Paulo, SP, 2008.

${ }^{24}$ Moreira, L. M.; Tese de Doutorado, Universidade de São Paulo, 2013.

${ }^{25}$ André, M.; Ludcke, M. Pesquisa em Educação: Abordagens qualitativas. 1986. Disponível em: < http://www.lite.fe.unicamp.br/papet/2003/e p145/pesq.htm>. Acessado em: 29 maio 2017.

${ }^{26}$ Bardin, L. Análise de conteúdo. Brasil, Edições 70, 2011. 
${ }^{27}$ Medina, M.; O teatro como ferramenta de aprendizagem da física e de problematização da natureza da ciência. Cad. Bras. Ens. Fís., v. 27, n. 2: p. 313-333, ago. 2010. Disponível em:

http://fisicadivertida.com.br/media/2015/07 Lo-teatro-e-a-fisica.pdf

${ }^{28}$ Moreira, L. M.; Marandino, M. Teatro de temática científica: conceituação, conflitos, papel pedagógico e contexto brasileiro. Ciência \& Educação (Bauru) 2015, 21, 511. [CrossRef]

${ }^{29}$ Sá, M. B. Z.; Vicentin, E. M.; Carvalho, E. A História e a Arte Cênica como Recursos
Pedagógicos para o Ensino de Química - Uma Questão Interdisciplinar. Química Nova na Escola 2010, 32, 9. [Link]

${ }^{30}{ }^{30}$ Vestena, R. F.; Pretto, V. O Teatro no Ensino de Ciências: Uma Alternativa Metodológica na Formação Docente para os Anos Iniciais. Vidya, 2012, 32, 9. [Link]

${ }^{31}$ Martins, P. H.; O metateatro no processo de formação teatral de crianças entre 08 e 12 anos. VI Congresso de Pesquisa e Pósgraduação em artes cênicas, 2010. [Link] 